\title{
MAKING SENSE OF ETHNOGRAPHY: FROM AN OUTSIDER PERSPECTIVE
}

\author{
Siti Ina Savira \\ Program Studi Psikologi Universitas Negeri Surabaya \\ e-mail:inasavira@yahoo.com
}

\begin{abstract}
This paper is aimed to compare two ethnographic works Learning to Labour, and Masculinity Beyond the Metropolis. The comparison is expected to illustrate how to make sense ethnographic work as a research methodology with its various types of epistemology and approach. The review will begin with a brief outline of the studies as described in each book and follow with further elaboration directed by several headings that covers Crotty (1998) four elements, namely epistemology, theoretical perspective, methodology, and method. It will also discuss the knowledge and values, and the theory of culture of each study.
\end{abstract}

Key words: Ethnography, knowledge, culture.

The first ethnographic work being discussed here is the one conducted by Willis (1977). Willis' work consists of one main case study and five comparative case studies. As comparison, Masculinity beyond the metropolis, conducted by J. Kenway, A. Kraack, and A. Hickey-Moody, is a multi-site ethnographic research. Both studies emphasised on participant observation as the main method of data collection, and therefore, claimed to be ethnographies. Both works also interested in young males culture; in fact Kenway, et al., (2004) was referring to Willis's (1977) as one of early ethnography research that gives valuable information on masculinity.

Willis study (1977) was conducted in 1972-1975 and was particularly interested at working culture, more specifically the transition of 'young non-academic disaffected males' from school to work force. He claimed to use qualitative method, case study, interview, group discussion, and participant observation and that the use of ethnographic format is unavoidable because of the nature of the topic in the study, which was about culture. Ethnography, according to Willis (1977), is the best method for the study because, most of all, it allow the respondents to speak for themselves and reach directly to the audience of the study.
The study wished to be able to explain the process of regeneration of the working class, how do young males adopt their roles, the values and culture, and how they perceive themselves in relation to others. The study found that the values and culture that they embrace were dominantly influenced by capitalism and patriarchal culture, where masculinity is perceived as superior. Young non-academic males believe that the men job is the physical job outside of the house. They consider mental works as girlish, so as engaging in school or being academic, since that means, according to them, is being passive. Masculinity also leads to superior and unfair view toward females. These values and culture are something they adopt from what they perceived as environment expectation of them. Therefore, to understand fully about counterschool culture, Willis (1977) concluded that outsiders' perspective is required.

Willis (1977) found that there is a space in cultural system that allows penetration or change. Therefore, he made some suggestion to approach the society to show them how culture can tell about who they are. Vocational education and classroom pedagogic strategies are called out to contribute in modifying perceived culture of the working classes.

The second study, Kenway, et al., (2004) study aimed to explore the effect of 
globalization in non-cities or not densely populated places in Australia, particularly on young males by focusing on their personal experience toward globalization that influence their identification of masculinity. The research involved three years of participant observation at natural setting fieldworks that involved four different places in Australia that further described and referred to as 'out of the way places'.

In each place, 36 young people were engaging in in-depth semi-structured interviews. Individual interviews to 24 young males and 12 young females aged 13 to 16 years old were conducted every week for six weeks periods. More informal conversation and some group discussions were also conducted toward parents, community members, teachers, and welfare service providers. Besides collecting observational data on the habits and the dynamic in the community as social organization, the data collection sources also covered documentaries on histories and government statistical data banks. Another source was derived from popular media and marketing representations of those places under study that give information about how masculinity and changes were represented. This type of source, according to Kenway, et al., (2004) is not common in ethnography. Furthermore, how Kenway, et al., (2004) defend their study trustworthiness will be embedded in more detail within the next section of this paper.

\section{Compare and contrast based on Crotty's four elements}

This section will discuss both works based on four elements as suggested by Crotty, namely epistemology, theoretical perspective, methodology, and method.

\section{Epistemology}

Epistemology can be defined as a way of making sense of what we know (Ambert, Adler, Adler, \& Detzner, 1995) by 'explaining how we know what we know' (Crotty, 1998). Epistemology implies the researcher beliefs about the nature of knowledge, therefore will determine the type of question and method he/she decided to use(Ambert, et al., 1995).

The two studies discussed here used two different epistemologies. Willis (1977) believes that the issue that he was interested in, which was labouring and the working class of 'young non-academic disaffected males' could only be understood from the insider point of view. He stated that 'Labouring is not a universal transhistorical changeless human activity. It takes on specific forms and meaning in different kinds of societies' (Willis , 197, p. 2). He represents the data he collected from interviews with key persons to show how he tried to make meanings out of it.

Therefore, I concluded that Willis (1977) was leaning toward constructionism, more specifically social construction. Constructionism can be understood as the view that believes 'that all knowledge, and therefore all meaningful reality as such, is contingent upon human practices, being constructed in and out of interaction between human beings and their world, and developed and transmitted within an essentially social context'(Crotty, 1998, p. 42).

This approach of epistemology is quite different from Kenway, et al., (2004). Although, like Willis's (1977), epistemology did not explicitly stated in the book, it can be assumed that Kenway, et al., (2004) epistemology is deconstruction. Kenway, et al., (2004) introduced the issue in the book by giving examples of how people commonly understand, or perhaps, misunderstand the 'places outside of densely populated cities', which he further describes as 'variously marginalized, stigmatized, pitied and patronized, romanticised and excoticised' (Kenway, 2004, et al., p. 3). The book raises an argument that such representation came from an overgeneralization of phenomenon by describing only the big picture and pattern of globalization, and analysing only particular 
aspects of globalization, particularly those aspects that seem to stand out or dominate and new and avoid the domain that requires ethical consideration and 'subjective' interpretation, such as personal experiences. The complexity of the phenomena would lie in the interpretation of the context and to make meaningful contradictories that may emerge from individual's point of view toward globalization as result of the dynamic interaction between people and place, for instance in places outside of densely populated cities, and how it affects the identification of manhood and masculinity. The book claims that research with deductive reasoning would tend to simplify context by generalizing and abstracting phenomena and therefore, failed to explain the complexity. The book claims to provide new way in understanding and analysing globalization and masculinity.

Deconstruction is built on the assumption that there is no final truth or pure objectivism, that meaning should be understood within the context that we choose to interpret and that it is dynamic and situational (Cilliers, 2005). Deconstruction argues about the complexity of finding meaning and that it should be understood within such complexity or without reducing or simplifying it, such as quantifying it. Therefore, to find meaning is to deal with 'normative and ethical domain' (Cilliers, 2005 , p. 259), and that such attempt to generalizing or abstracting phenomenon would mean 'ethical emptiness' (Kenway, et al., 2004). Seale (2012) defines deconstruction as an approach that purpose is to challenge mainstream theory by providing alternative explanation or different view point as opposed to authority by representing social actors view points as well as the researchers' themselves.

\section{Theoretical perspective}

Theoretical perspective or the lenses through which researcher grounds their criteria and context of both studies is interpretivism. Interpretivism argues that reality is a social construction rather than objectively determined (Kelliher, 2005; Walsham, 1995). Interpretivism requires researcher to interact with their human subject to build meaning, which will be reflected on the methodology and method. More specifically, Willis (1977) used symbolic interactionism to derive his interpretation to what his respondents were saying. Symbolic interactionism requires researcher to be fully immerse into the society that they study in order to be able to understand their perspective, value, and culture (Crotty, 1998).

Two major theories that Kenway, et al., (2004) used are masculinity and globalization (p.4). Although the study introduced some pre-existing research and theories on masculinity and globalization, the purpose of the study was not to test the theories but rather to build meaning from the human subjects they were going to observe in the fieldwork. The theories were useful to show the gap in existing literatures and clarify the links of elements being studied (Ambert, et al., 1995). For instance, Kenway, et al., (2004) found that existing theories and literatures had failed to recognize the uniqueness of the place and the people in understanding globalization, particularly how it affects how they identify themselves and others. They also theoretically explain and justify how masculinity related to globalization. However, unlike positivistic research, the theories would not limit or determine the analysis and the findings of the study.

\section{Methodology}

Although both studies are ethnography, each used different strategy in approaching the issue they were interested in. Willis (1977) was using one main case study and five comparative studies. Willis (1977) argued that ethnography is best suited to his needs in the study because it has 'a sensitivity to meanings and values as well as an ability to represent 
and interpret symbolic articulations, practices, and forms of cultural production', it also allow 'human agency within the object of study' to permeate to analysis and the readers (p.3).

Kenway, et al (2004), however, specified their methodology as global ethnography, in particular is place-based ethnography. Kenway, et al., (2004) provides an extensive justification for their approach in chapter 2. They elaborate discussion about globalization and ethnography, how both are often considered as 'mismatched' and how to address this issue. They concluded there are three points that global ethnography must achieve. First, it must be sufficiently rich to capture the movement or changes of space, time, place, and identity. This can be achieved by including in the analysis some considerations toward 'large-scale economic and cultural shifts and influences, their social and cultural manifestations in place and space, and their implications for identity and the imagination'(Kenway, et al., 2004, p. 50). This notion aligns with Ambert, et al., (1995) about 'validating' qualitative research. Particularly in ethnography, providing thick description (Geertz, 1973) or adequate description (Silverman, 1985), representing many layers of realities and conducting many observations (Kirk and Miller, 1986) or collecting multisource of data collection can help increase the trustworthiness of the study (as cited in Ambert, et al., 1995, p.885).

Second, ethnography 'must include theories and techniques that help to make sense of complex, uneven, and diverse globalizing trajectories and local-global', and allow the comparison on its manifestation (Kenway, et al., p. 50). In addition to that Ambert, et al., (1995) also suggest that a qualitative research should at least explicitly describe detailed approach and strategy they adopt in their research. And finally, ethnographers must expand the field of their study to be able to capture a more precise definition of globalization. Ambert, et al.,
(1995) argues about the importance of involving 'adequate sample'. A qualitative researcher must have a sensitivity to recognize the complexity of the study to determine 'the size and parameter of the sample'. Kenway, et al., (2004) also discuss about ethnography and masculinity by elaborating supporting notions about the contribution of ethnographic work in understanding masculinity.

\section{Method}

The method used in both studies is quite similar, where it involves participant observation, interviews, and group discussion. However, Kenway, et al (2004) also used documentary analysis, such as historical documents and government statistical data, and some analysis on media sources that represents masculinity, gender issues, and change. The latter, as admitted by Kenway, et al., (2004) is out of convention. However, Kenway, et al., (2004) argue that media cannot be taken away from discussion on globalization, since it is one of globalization mean to spread.

\section{The Knowledge and its Value}

Willis (1977) study has become one of important work in ethnography particularly in masculinity and schools. The study was trying to understand the transitional process of young non-academic disaffected males from school culture to working culture. It tried to understand how and why do these young males take on their identity of masculinity in relation to labour or working class. The study was conducted as the boys were at their last year of school and their first year outside school. The study findings were extensive, including some understanding on the values and culture the boys adopt that recognized as 'counter-school culture' and how capitalism affect their values of masculinity and their perceived role of being part of a working class.

The study tried to raise awareness about the importance of the school as media from 
which an action toward a cultural system can be done. Willis (1977) argues that school has a significant role to influence change of the 'counter-school culture' of young nonacademic disaffected males. Vocational education and classroom pedagogy strategy, for instance, are some means to approach such culture.

The study of Kenway, et al., (2004) was based on the argument that there were not many research or literatures that tried to link or explain how masculinity and globalization are related to one another, despite the huge amount of research that has been conducted on each topic. Therefore, masculinity has little understanding about globalization and vice versa. One reason is because previous research on globalization emphasising on making generalization and abstraction and in result, ignoring the unique context of the people and the place. They also criticised 'metrocentric' view in analysing masculinity and globalization that resulting in marginalizing out-of-way-places. Therefore, their study was conducted based on place-based ethnography that aimed to raise issue of 'unevennes' of globalization as it has not yet been captured by previous theory on globalization.

As a research method, they expect the study to be an example of applying placebased global ethnography that covers the discussion on critical ethnography, particularly in discussion on masculinity and globalization. They also predict that the study would raise question about the 'role of the imagination in social life' and the role of the media that often serve as a tool of imagining place and global connections between places with similar global issues.

\section{Theory of Culture}

Ethnography is closely associated with cultural studies; that is, a research that investigate the ways of how people use 'culture' as way of life in social context, and of ways in making culture (Gray, 2003).
Although it is not explicitly stated, the theories of culture used in each book will be described briefly.

The two studies have a similar theory of culture in a way that they both believe that culture is socially constructed. However, Willis (1977) was particularly interested in a specific culture that he referred to as 'counterschool culture' and tried to understand it from the insider's point of view, that is, the young non-academic and disaffected males. He tried to understand how this particular group perceive their own culture of gangs and as opposed to 'school culture' or 'formal culture'. He tried to capture their values and attitudes and what that means to them, for instance, drinking during lunch time, being sexually active and attractive, being part of a gang or 'the lads', smoking, and so on.

Kenway, et al., (2004), on the other hand, was trying to give a different perspective in understanding culture as affected by globalization, which they claimed have not yet sufficiently discussed. Kenway, et al., (2004) argues that place and space are important in understanding culture, since both are the intersections of the past and the present. Within space and place also that young males are linked to the global spaces in terms of multiple forces, imagination, and connection, as outlined by Massey's (1994) concept of spaces and place where they would continually rethink and reshape their identity. Globalization has become an influence that informs and links people and places, however not in that similar or general huge context, but rather as something that young males draw on in their context of space, time, and place in order to make identification of who they are, particularly on issue of masculinity. Therefore, the media became an important part of globalization that allows 'imagination' of the places beyond where they live. Culture, therefore, is socially constructed and dynamic. 


\section{CONCLUSION}

Ethnography, as shown by both study, is a valuable methodology to explore in depth a particular culture within a particular context and society. The information generated from this methodology can be very extensive beyond theoretical framework. It is also apparent that the sensitivity in data collection and the interpretation skill of the researcher are crucial to have an adequate analysis over massive data collected from an extensive period of time and report it in interrelated and comprehensive way.

In comparison, although both studies discussed in this paper are ethnographies, but both were using different approach and purposes. Both studies showed that ethnography is an adequate methodology in research and that it can contribute to theoretical and practical development. Kenway, et al., (2004) in particular, had presented their study with arguments to justify ethnography as an appropriate methodology for the study. The studies also shown the major opportunity for many approaches in ethnography to be developed depending on the issue being investigated and that it is depends on the researcher to best utilize that opportunity.

\section{REFERENCES}

Ambert, A., Adler, P. A., Adler, P., \& Detzner, D. F. (1995). Understanding and evaluating qualitative research. Journal of Marriage and Family, 57(4 (Nov., 1995)), 879-893.

Cilliers, P. (2005). Complexity, Deconstruction and Relativism. Theory, culture, and society, 22, 255267. doi: $10.1177 / 0263276405058052$

Crotty, M. (1998). Foundations of social research. London: SAGE Publications.

Gray, A. (2003). Research practice for cultural studies. London: SAGE.

Kelliher, F. (2005). Interpretivism and the pursuit of research legitimisation: An integrated approach to single case design. The electronic journal of business research methodology,3 (2), 123-132.
Kenway, J., Kraack, A., \& Hickey-Moody, A. (2004). Masculinity beyond the Metropolis: Palgrave Macmillan.

Seale, C. (2012). Researching Society and Culture (3rd ed.). Los Angeles: SAGE.

Walsham, G. (1995). The emergence of interpretivism in IS research. Information systems research, 6:4(December, 1995), 376-394.

Willis, P. (1977). Learning to labour: How working class kids get working class jobs Saxon House, Farnborough. 